\title{
Repensar la docencia universitaria
}

por Manuale, Marcela ${ }^{1}$

... De los miedos nacen los corajes; y de las dudas, las certezas. Los sueños anuncian otra realidad posible y los delirios, otra razón. Al fin y al cabo somos lo que hacemos para cambiar lo que somos...

Eduardo Galeano

¿Qué es lo más importante que inventé este año?

Edith Litwin

La problemática de la enseñanza es un área de preocupación actual de las instituciones de nivel superior.

Pero durante mucho tiempo, la universidad como institución formadora, encargada de la transmisión de los contenidos científicos y culturales, se desentendió de las modalidades que puede adoptar la enseñanza, valorizando exclusivamente la imagen del docente universitario como experto en contenidos. En el dominio de los contenidos se centró el resguardo de la calidad universitaria, independientemente de las formas en que esos contenidos fueron puestos a disposición para el aprendizaje de los estudiantes.

A pesar de los nuevos escenarios en el ámbito socio-político, los avances en el mundo de las ciencias como de las nuevas tecnologías y los nuevos actores que ingresan a la universidad, no se han alterado sustancialmente las formas de comunicación didáctica en el aula universitaria.

Como sostiene Elisa Lucarelli (2004), el docente universitario es reconocido por el alto nivel de preparación académica y profesional en su campo disciplinar, sin que esta formación necesariamente esté acompañada por conocimientos específicos sobre la práctica de la enseñanza, que le permitan dar una respuesta adecuada y científicamente fundamentada, a las nuevas problemáticas que afectan al aula universitaria.

\footnotetext{
${ }^{1}$ Directora de la revista Aula Universitaria y responsable del Gabinete Pedagógico de la Facultad de Bioquímica (UNL).
} 
Por lo tanto, podemos decir que existe todavía una tensión entre los saberes pedagógicos y los contenidos de la propia formación disciplinar. Históricamente, en la universidad no se ha reconocido en forma adecuada la dimensión pedagógica del desempeño docente, la cual fue apagada por la valoración casi excluyente del dominio del conocimiento disciplinar (la especificidad científica, artística o humanística), donde se puso el énfasis para considerar la excelencia del docente universitario.

$\mathrm{Si}$ bien es relevante dominar con experticia el área disciplinar para un buen desempeño docente, también es significativo el conocimiento pedagógico que le posibilite al docente universitario articular la teoría con la práctica en la enseñanza del nivel superior.

El docente universitario construye su propia identidad en el contexto institucional donde desarrolla sus prácticas. Se asume como actor principal en la producción del conocimiento, pero contrasta con el escaso reconocimiento social de la necesidad de formarse en el campo pedagógico. Para los docentes de los otros niveles del sistema educativo, hay una larga tradición en cuanto a su formación específica como profesionales de la educación. Sin embargo, en relación al docente universitario no está muy clara cuál es la práctica profesional que define su situación en la institución: ¿la práctica de enseñar? ¿la práctica específica para cual fue formado en su campo particular?. "El docente universitario se reconoce a sí mismo por su profesión de origen y se identifica con el título otorgado por la unidad académica donde se graduó. La legitimidad profesional de sus prácticas como médico, ingeniero, bioquímico, contador, es indiscutida, se origina en un saber acreditado escolarmente y cuenta con mayor o menor grado de aprobación. El poder y el prestigio no provienen de la docencia universitaria como saber pedagógico, sino del dominio de un campo científico, tecnológico o humanístico determinado." (Lucarelli, E. 2004)

El contexto actual plantea múltiples desafíos a la universidad y reclama nuevas prácticas y nuevos modos de enseñar y aprender en forma crítica y reflexiva. El cambio educativo requiere no solo de una transformación didáctica y curricular sino también personal, a partir de la construcción de una nueva profesionalidad docente.

Reconocemos que la enseñanza es una tarea compleja y que no se trata de un trabajo técnico sino de un auténtico esfuerzo profesional, que coloca en el centro de discusión a una sistemática reflexión acerca del para qué, del qué enseñar, a quiénes y en qué contexto enseñar.

Hace falta repensar la docencia en la universidad y desarrollar una didáctica universitaria que se preocupe por la comprensión y búsqueda de estrategias alter- 
nativas a la enseñanza tradicional y rutinaria, que posibiliten en los estudiantes el desarrollo de procesos orientados a la construcción del conocimiento.

Es imprescindible para una didáctica del nivel superior, una mirada contextualizada acerca de la enseñanza, reconociendo la especificidad de los problemas que se presentan al interior de cada campo disciplinar de formación, poniendo en un lugar relevante al contenido a enseñar como componente de ese contexto.

El interés por la comprensión de los procesos peculiares que se dan en estos espacios, de sus formas de manifestación y de sus problemas, posibilita evitar las miradas simplificadoras que derivan de la pretensión, engañosamente ilusoria, por encontrar estrategias de intervención únicas diseñadas sin tener en consideración las peculiaridades de cada contexto. (Lucarelli, 2010).

También hace falta una "didáctica de autor" en la enseñanza universitaria, como señala Edith LITWIN (2009): "La didáctica superior, la de esa universidad del futuro que proponemos es, más que otra cosa, la didáctica de autor, una construcción original en la que cada profesor crea, acorde con su experticia un diseño personal que permitirá la construcción del conocimiento en el aula." LITWIN, E. (2009)

Esta didáctica de autor se inscribe en las nuevas líneas de investigación didáctica, y nos permitiría entender por qué los mejores profesores (Bain, 2007) son reconocidos por los propios estudiantes como los que tienen una gran capacidad de comunicación y altas expectativas en relación al aprendizaje de sus alumnos, a quienes entusiasman y les prometen mucho del conocimiento que van a compartir. Los buenos profesores dominan muy bien su campo disciplinar y pueden explicar y simplificar temas o conceptos muy complejos, piensan de manera personal e idiosincràtica la propia disciplina, y pueden saltar esas fronteras disciplinares, utilizan las metáforas y el arte para pensar los contenidos y muestran constantemente su pasión por el conocimiento.

Repensar la docencia universitaria en función de nuevos marcos teóricos y de nuevas prácticas de enseñanza nos permitirá conjugar la teoría con la práctica, para lograr aprendizajes más significativos y relevantes.

La didáctica, entendida como el conocimiento contextualizado de las prácticas de enseñanza, nos permitirá avanzar en procesos reflexivos sobre nuestro accionar docente en la universidad y pensar en innovaciones que articulen propuestas de enseñanza de los saberes disciplinares, buscando para cada contenido la mejor forma de enseñarlo. La preocupación por mejores aprendizajes debe guiar los esfuerzos de mejora en las aulas universitarias. 